\title{
Subjetividad y esfera pública: el género y los sentidos de familia en las memorias de la represión
}

\author{
Subjectivity and the public sphere: the place of gender \\ and family in memories of repression
}

\author{
Elizabeth JeLIN \\ CONICET - IDES \\ elijelin@gmail.com
}

Recibido: 10.11.2010

Aprobado definitivamente: 03.06.2011

\section{RESUMEN}

Este texto toma como foco las dimensiones de género y familia - especial pero no exclusivamente en maternalismo- - El análisis y la reflexión apuntan a elucidar la manera en que estas nociones culturalmente construidas se manifiestan en las memorias del pasado reciente en la experiencia del Cono Sur de América Latina, particularmente en Argentina. La dimensión de género se manifiesta de dos maneras simultáneas y convergentes: en la forma en que mujeres y hombres dan sentido a la violencia política vivida, y en el lugar emblemático que tienen las imágenes familiares y maternales en las memorias de ese pasado. Esto último, a su vez, convierte al vínculo de parentesco en la fuente central de legitimidad de la palabra — contraponiéndose a la ampliación ciudadana del tema-.

Palabras Clave: Memoria social, familismo, género, maternalismo, América Latina.

\begin{abstract}
This paper deals with the ways in which gender and the family are symbolically present in the processes linked to memories of recent repressive pasts. The paper is based on the actual experience of social groups in the Southern Cone of Latin America, particularly in Argentina. The gender dimension can be seen in the ways in which women and men remember and silence the past violence, and in the emblematic place taken up by familistic and maternalistic images of the past. The centrality of kin relations in defining legitimacy of voice hinders a wider civic commitment to the issues involved.
\end{abstract}

KEYwords: Social Memory, Familism, Gender, Maternalism, Latin America.

\section{SUMARIO}

1. Las memorias, los olvidos y los silencios. 2. La represión tiene género. 3. La familia en las políticas de la represión y la resistencia. 4. El género en las memorias. 5. Las paradojas de la escucha institucional. 6. El familismo y el maternalismo en la esfera pública. 
El objetivo de este texto es presentar algunas reflexiones sobre la manera en que la dimensión de género y los sentidos de la noción de familia se ponen en juego - a través de su presencia y su silencio- en las memorias de pasados recientes dictatoriales, llenos de violencia y represión política. Estas reflexiones se basan especialmente en la experiencia del Cono Sur de América Latina, particularmente en Argentina.

Es en el plano de la subjetividad de las memorias donde la dimensión de género se manifiesta de manera más clara e inmediata. Esto ocurre de dos maneras simultáneas y convergentes: en la forma en que mujeres y hombres han buscado dar algún sentido a la violencia, y en el proceso por el cual las imágenes familiares y maternales han ido ocupando un espacio emblemático en las memorias de ese pasado. Elegir hablar de los procesos subjetivos, sin embargo, no debe ser interpretado como una jerarquización de los espacios sociales y planos analíticos en los cuales se despliegan los procesos de memoria. Los planos y niveles de análisis de las memorias son múltiples y con interacciones complejas: desde los procesos personales de sobrevivientes (el testimonio, los silencios) hasta las representaciones y performances simbólicas y culturales, incluyendo por supuesto las prácticas institucionales estatales - juicios, reparaciones económicas, monumentos, conmemoraciones oficializadas y/o la elaboración de una nueva legislación-.

El análisis de la memoria implica un primer reconocimiento: que se trata siempre de memorias plurales, en espacios de conflicto y lucha. Cuando participan en las luchas por las memorias en la esfera pública, hay por parte de los actores la intención o voluntad de presentar una narrativa del pasado, y las luchas son por intentar imponer $s u$ versión del pasado como hegemónica, legítima, "oficial", normal, o parte del sentido común aceptado por todos/ as. En estas luchas, el Estado juega un papel fundamental, pues es en ese espacio institucional donde se plantean las demandas de justicia. Las luchas contra la impunidad son siempre luchas que se dan en el espacio institucional, confrontando al Estado.

En las experiencias recientes en el Cono Sur, las instancias estatales y las organizaciones ligadas a los reclamos por las violaciones del pasado encuadradas en el movimiento de derechos humanos son los actores y protagonistas centrales, aunque no únicos. Juntos -a través de decisiones estatales, de prácticas sociales de conmemoración, de imágenes transmitidas en el documento y en la ficción-han contribuido a conformar sentidos culturales y simbólicos del pasado reciente. Como veremos más abajo, los estereotipos más "tradicionales" de género no pudieron ser superados en estos procesos de construcción simbólica.

\section{LAS MEMORIAS, LOS OLVIDOS Y LOS SILENCIOS ${ }^{1}$}

La vida cotidiana está constituida fundamentalmente por rutinas, comportamientos habituales, no reflexivos, aprendidos y repetidos. El pasado del aprendizaje y el presente de su memoria se convierten en hábito y en tradición. No hay nada "memorable" en el ejercicio cotidiano de estas memorias. Estos comportamientos, claramente "enmarcados" (en el sentido de Halbwachs) socialmente en la familia, en la clase y en las tradiciones de otras instituciones, son a la vez individuales y sociales. Están incorporados de manera singular para cada persona. Al mismo tiempo, son compartidos por los miembros de un grupo social. Se trata de hábitos del vestir y de la mesa, formas de saludar a hombres y a mujeres, a extraños y a cercanos, manejos corporales en público y en privado, formas de expresión de los sentimientos. La lista de comportamientos aprendidos donde funciona rutinariamente una "memoria habitual" es interminable.

Los quiebres en esas rutinas esperadas involucran al sujeto de manera diferente. Se juegan allí afectos y sentimientos, que empujan a la reflexión y a la búsqueda de sentido. Como señala Bal (1999: viii) es este compromiso afectivo lo que transforma esos momentos y los hace "memorables". La memoria es entonces otra, se transforma. El acontecimiento o el momento cobran una vigencia asociada a emociones y afectos. El acontecimiento rememorado o "memorable" será entonces expresado en forma narrativa, convirtiéndose en la manera en que el sujeto cons-

${ }^{1}$ El marco analítico que guía este trabajo está desarrollado de manera más completa en Jelin, 2002. 
truye un sentido del pasado, una memoria que se expresa en un relato comunicable, con un mínimo de coherencia. También con huecos y silencios.

Esta construcción tiene dos notas centrales. Primero, el pasado cobra sentido en su enlace con el presente en el acto de rememorar/olvidar. Esto ubica directamente el sentido del pasado en un presente, y en función de un futuro deseado. El presente contiene y construye la experiencia pasada y las expectativas futuras. La experiencia es un "pasado presente, cuyos acontecimientos han sido incorporados y pueden ser recordados" (Koselleck, 1993: 338). Ubicar temporalmente a la memoria significa hacer referencia al "espacio de la experiencia" en el presente. El recuerdo del pasado está incorporado, pero de manera dinámica, ya que el sentido dado a las experiencias en un momento dado puede modificarse en períodos posteriores. "Los acontecimientos de 1933 sucedieron definitivamente, pero las experiencias basadas en ellos pueden modificarse con el paso del tiempo. Las experiencias se superponen, se impregnan unas de otras" (Koselleck, 1993: 341).

Estamos hablando, entonces, de procesos de significación y resignificación subjetivos, donde los sujetos de la acción se mueven y orientan en un presente que se tiene que acercar y alejar simultáneamente de esos pasados recogidos en los espacios de experiencia y de los futuros incorporados en horizontes de expectativas. Esos sentidos se construyen y cambian en relación y en diálogo con otros, que pueden compartir y confrontar las experiencias y expectativas de cada uno, individual y grupalmente.

A su vez, hay vivencias pasadas que reaparecen de diversas maneras en momentos posteriores, pero que no pueden ser integradas narrativamente, a las que no se les puede dar sentido. Es la imposibilidad de dar sentido al acontecimiento pasado, la imposibilidad de incorporarlo narrativamente, que coexiste con su presencia persistente y su manifestación en síntomas, lo que indica la presencia de lo traumático. En este nivel, el olvido no es ausencia o vacío. Es la presencia de esa ausencia, la representación de algo que estaba y ya no está, borrada, silenciada o negada. ${ }^{2}$

En lo dicho hasta ahora se pueden distinguir dos tipos de memorias, las habituales y las narrativas. Hay aquí una primera nota importante para el tema que nos convoca, memoria y género, ya que hay diferencias entre mujeres y varones en los roles sociales predominantes, así como en la importancia social asignada a esos roles. En tanto las mujeres tienden a estar a cargo de tareas "habituales" (¿qué hay más habitual que limpiar, lavar, cocinar y cuidar a los demás?) parecería que las mujeres no tendrían nada memorable para contar. El desafío es entonces convertir lo habitual en memorable. Y en incorporar lo habitual en las memorias de los hombres.

En todo esto, el olvido y el silencio ocupan un lugar central. Toda narrativa del pasado implica una selección. La memoria es selectiva, y la memoria total es imposible. A menudo, pasados que parecían olvidados "definitivamente" reaparecen y cobran nueva vigencia a partir de cambios en los marcos culturales y sociales que impulsan a revisar y dar nuevo sentido a huellas y restos, a los que no se había prestado atención durante décadas o aun siglos. Pensemos por ejemplo en la incorporación de un encuadre interpretativo de los pueblos originarios de América para releer la historia de cinco siglos - historias y memorias que presuntamente habían sido "olvidadas" durante tanto tiempo-.

Los borramientos pueden también ser producto de una voluntad o una política de olvido y silencio por parte de actores que elaboran estrategias para ocultar y destruir pruebas y rastros que impidan las pruebas de lo ocurrido en tiempos futuros - recordemos la célebre frase de Himmler cuando declaró que la "solución final" fue una "página gloriosa de nuestra historia, que no ha sido jamás escrita, y que jamás lo será"- ${ }^{3}$ En casos así, hay un acto político voluntario de destrucción de pruebas y huellas, con el fin de promover olvidos selectivos a partir de la eliminación de pruebas documentales. Sin embargo, los recuerdos y memorias de protagonistas

\footnotetext{
${ }^{2}$ Sin embargo, no se trata de una imposibilidad absoluta o un borramiento total de la capacidad de dar sentido. El trauma no invade la totalidad del sujeto. Más bien, lo que se encuentra son brechas y huecos de sentido, tensiones narrativas y silencios aparentemente inexplicables (La Capra, 2001).

${ }^{3}$ Himmler dijo esta frase a los generales de las SS el 4 de Octubre de 1943. Citada por William Shirer (1967), The rise and fall of the Third Reich, Londres, Fawcett Press: 1259. Agradezco a Cacho Lotersztain el haberme señalado los detalles y las fuentes para este dato.
} 
y testigos no pueden ser manipulados de la misma manera, excepto a través de su exterminio físico. En esta dirección, toda política de conservación y de memoria, al seleccionar huellas para preservar, conservar o conmemorar, tiene implícita una voluntad de olvido. Pero también produce prácticas de resistencia y reacciones que llevan a otros/as a mantener vivas - aunque a menudo ocultas - otras interpretaciones y otras narrativas del pasado.

Aquí llegamos a los silencios. Existen silencios impuestos por temor, que van desde los silencios acerca de la violencia doméstica o el acoso sexual en lo interpersonal, hasta los silencios políticos, que hemos vivido tan de cerca en los regímenes políticos dictatoriales de la España franquista o las dictaduras del Cono Sur. En estos casos, sobreviven recuerdos dolorosos que esperan el momento propicio para ser expresados (Pollak, 2006). Silencios por temor, pero también silencios para proteger y cuidar a los/ as otros/as, para no herir ni transmitir sufrimientos. Silencios para poder "seguir viviendo" y compartir la vida.

Hay una lógica adicional que explica el silencio. Para relatar es necesario encontrar del otro lado la voluntad de escuchar (Laub, 1992; Pollak, 1990). En el plano de las memorias individuales, el temor a no ser comprendido/a también lleva a silencios. Encontrar a otros/as con capacidad de escuchar es central en el proceso de quebrar silencios. Quizás sea esta ausencia de capacidad de escucha y su aparición muchos años después lo que ha llevado primero a las mujeres chilenas a silenciar la violación sexual como práctica represiva, para dejar salir públicamente todos esos silencios sólo muchos años después, cuando se abrió un espacio institucional legítimo de escucha a través de Comisión Nacional sobre Prisión Política y Tortura.

En suma, la "experiencia" es vivida subjetivamente y es culturalmente compartida y compartible. Es la acción humana la que activa el pasado, corporizado en sus diversos contenidos. La memoria, entonces, se produce en tanto haya sujetos que comparten una cultura, en tanto haya agentes sociales que intentan "materializar" sentidos del pasado en espacios institucionales legítimos tales como comisiones, informes y juicios. También en testimonios y narrativas, en diversos productos culturales que son concebidos o que se convierten en vehículos de la memoria: testimonios, libros, museos, monumentos, películas, textos de historia, o actuaciones y expresiones que, antes que re-presentar el pasado, lo incorporan performativamente (van Alphen, 1997).

\section{LA REPRESIÓN TIENE GÉNERO}

Como bien sabemos, la represión de las dictaduras del Cono Sur tuvo especificidades de género. Los impactos fueron diferentes en hombres y mujeres, hecho obvio y explicable por sus posiciones diferenciadas en el sistema de género, posiciones que implican experiencias vitales y relaciones sociales jerárquicas claramente distintas.

Las experiencias represivas corporales propiamente dichas, relativas a las víctimas directas de tortura, prisión, desaparición, asesinato y exilio, muestran diferencias entre hombres y mujeres, ligadas al sistema de género imperante. El golpe militar de 1973 en Chile fue dirigido hacia un gobierno socialista en ejercicio. La concentración de la represión sobre funcionarios y políticos que ejercían cargos gubernamentales implicó una presencia proporcional mayor de hombres adultos entre las víctimas directas. En Argentina, Uruguay y Brasil la represión más violenta estuvo dirigida a grupos militantes (incluyendo movimientos guerrilleros armados), donde había una fuerte presencia juvenil. La división sexual del trabajo imperante en estos países implica que los hombres son (y lo eran mucho más en los años sesenta y setenta) más numerosos que las mujeres en los roles "públicos" y en la militancia política y sindical. La diferencia entre la participación de hombres y mujeres fue menor en el movimiento estudiantil y en los movimientos armados, donde ya en esa época, la presencia de mujeres era significativa.

También el poder que se ejerció en la represión directa se da en el marco de relaciones de género. El modelo de género presente identificaba la masculinidad con la dominación y la agresividad, características exacerbadas en la identidad militar, y una feminidad ambivalente, que combinaba la superioridad espiritual de las mujeres (inclusive las propias ideas de "Patria" y de "Nación" están feminizadas) con la sumisión y pasividad frente a los deseos y órdenes de los hombres. Los rituales del poder en el escenario público (saludos militares, desfiles, etc.) tenían un carácter performativo, en el que se desplegaba sin matices la dualidad entre el actor/poder masculi- 
no por un lado y la pasividad/exclusión feminizada de la población o audiencia por el otro.

El poder masculino militar en la esfera pública, con sus rituales y prácticas de representación repetitivas en uniformes, desfiles, exhibición de armas, etc., se acompañaba con performances materializadas en cuerpos y en prácticas concretas en los espacios específicos de la represión, en los lugares de tortura. En efecto, allí la masculinidad de los torturadores se afirmaba en su poder absoluto para producir dolor y sufrimiento. La tortura era parte de una "ceremonia iniciática" en los campos de detención, en que se privaba a la persona de todos los rasgos de su identidad: la vestimenta, las pertenencias personales, la posibilidad de mirar y ver por capuchas y mordazas. "La propia humanidad entra en suspenso (...). La capucha y la consecuente pérdida de la visión aumentan la inseguridad y la desubicación (...). Los torturadores no ven la cara de su víctima; castigan cuerpos sin rostro; castigan subversivos, no hombres" (Calveiro, 1998: 62). El uso de apodos animales - Tigre, Jaguar, Puma - y las ceremonias iniciáticas de los nuevos miembros de los equipos torturadores fueron "momentos de exaltación, cuando el torturador se sentía como Dios, con poder para reducir al/a la otro/a a ser una víctima pasiva, a un cuerpo a ser penetrado" (Franco, 1992: 107).

La represión directa a mujeres podía estar anclada en su carácter de militantes activas. Pero además, las mujeres fueron secuestradas y fueron objeto de represión por su identidad familiar, por su vínculo con hombres - compañeros y maridos especialmente, también hijos - con el fin de obtener información sobre actividades políticas de sus familiares-. La identificación con la maternidad y su lugar familiar, además, colocó a las mujeres-madres en un lugar muy especial, el de responsables por los "malos caminos" y desvíos de sus hijos y demás parientes (Filc, 1997).

Todos los informes existentes sobre la tortura indican que el cuerpo femenino fue un objeto "especial" para los torturadores. El tratamiento de las mujeres incluía una alta dosis de violencia sexual. Los cuerpos de las mujeres - sus vaginas, sus úteros, sus senos-, ligados a la identidad femenina como objeto sexual, como esposas y como madres, eran claros objetos de tortura sexual (Bunster, 1991; Taylor, 1997).

Para los hombres, la tortura y la prisión implicaban un acto de feminización, en el sentido de transformarlos en seres pasivos, impotentes y dependientes. La violencia sexual era parte de la tortura, así como una constante referencia a la genitalidad - la marca de la circuncisión entre víctimas judías como factor agravante de la tortura, las referencias al tamaño del pene para todos, la picana en los testículos, etc.- ${ }^{4}$ Era una manera de convertir a los hombres en seres inferiores y, en ese acto, establecer la "virilidad" militar. Los hombres tenían que "vivir como mujeres", tomando conciencia de sus necesidades corporales: "ser como una mujer o morir como un hombre" (para un testimonio, ver Tavares, 1999).

La polarización entre lo masculino/femenino, activo/pasiva, estaba naturalizada entre los militares. También lo estaba en los grupos guerrilleros y en la sociedad como un todo. En las representaciones de la guerrillera por parte de los medios de comunicación de masas en la Argentina dictatorial, la ambigüedad de esta feminidad está presente. Por un lado, aparece una imagen de mujer masculinizada, con uniforme y armas, un cuerpo que rechaza todo rasgo "femenino". Como contrapartida, también en el movimiento guerrillero había dificultades para integrar la feminidad de las mujeres militantes. La aceptación de las mujeres quedaba siempre en duda, y cuando demostraban su habilidad en operativos armados, eran vistas como "pseudo-hombres" (Franco, 1992: 108).

Dado el sistema de género en las relaciones familiares, además de ser víctimas "directas", las mujeres fueron básica y mayoritariamente víctimas "indirectas", y éste es el rol en el que se las visualiza más a menudo: como familiares de víctimas - madres y abuelas principalmente; en menor medida esposas, hermanas, hijas, novias- Al tomar como rehenes a los hombres, el sistema represivo afectó a las mujeres en su rol familiar y de parentesco, es decir, en el núcleo de sus identidades tradicionales de mujer y esposa. Desde esos lugares, y como mecanismo para poder sobrevivir y sobrellevar sus

\footnotetext{
${ }^{4}$ La performance activa de la violación sexual entre hombres, que es la que realizaban los torturadores, no era identificada con la homosexualidad ni con ser "afeminado". Es el rol sexual "pasivo" de ser penetrado el que feminiza (Saléis, 1995; Taylor, 1997).
} 
"obligaciones familiares", las mujeres movilizaron otro tipo de energía, basada en sus roles familiares "tradicionales", anclada en sus sentimientos, en el amor y en la ética del cuidado - lógica que difiere de la política-.

Dos tipos de acciones "típicamente femeninas" se dieron en ese contexto: en la escena pública, la creación de organizaciones de derechos humanos ancladas en el parentesco con las víctimas directas, cuestión que analizaremos más abajo. En el ámbito privado, se trató de la lucha por la subsistencia familiar y la adaptación o cambio en función de las nuevas circunstancias. Las mujeres-madres debieron hacerse cargo del mantenimiento y la subsistencia familiar cuando los hombres fueron secuestrados o encarcelados. Muchas mujeres se convirtieron en las principales sostenedoras del hogar. En esas condiciones, y basándose en sentimientos y responsabilidades familiares, las mujeres debieron movilizar sus recursos personales para cuidar y alimentar, a veces en el espacio doméstico hogareño, otras en iniciativas comunales tales como ollas comunes y pequeñas empresas cooperativas.

Las tareas de la domesticidad y las responsabilidades ancladas en el parentesco son actividades que muchas mujeres deben llevar a cabo solas en diversos contextos sociales, en diversas circunstancias personales (divorcios, abandonos), y están ligadas a menudo a condiciones de pobreza. La situación de las mujeres que debieron hacerse cargo de esas tareas debido al secuestro-desaparición, al encarcelamiento o a la clandestinidad de sus compañeros es intrínsecamente diferente, para ellas y para sus hijos y demás familiares. En primer lugar, porque la situación de terror en que se vivía requería ocultamientos diversos, inclusive del dolor personal. Incluía intentar que los hijos siguieran sus actividades cotidianas "como si nada hubiera pasado", para evitar sospechas. El miedo y el silencio estaban presentes de manera constante, con un costo emocional muy alto. Además, en numerosos casos la soledad fue un rasgo central de la experiencia: sea para no comprometer a otros parientes y amigos, sea por el alejamiento de éstos por miedo o por desaprobación social, el entramado social en el que normalmente se desarrollan las actividades cotidianas de la domesticidad fue totalmente destruido, quebrado, fracturado (Ciollaro 1999). ${ }^{5}$

Por supuesto, los hombres también fueron víctimas "indirectas". Y aquí, en líneas generales, son ellos los que se han vuelto invisibles. Poco se sabe sobre esta experiencia personal. En parte, la vivencia de ser compañero de una mujer activista y militante sin presencia pública propia no fue muy extendida. Esta constelación familiar de hombres con compañeras desaparecidas haciéndose cargo de la domesticidad tiende a ser invisibilizada, porque contradice las expectativas y los patrones sociales "normales".

\section{LA FAMILIA EN LAS POLÍTICAS DE LA REPRESIÓN Y LA RESISTENCIA}

En Argentina, los lazos familiares y la imagen de la familia tienen un lugar muy particular a partir de la dictadura militar y el terrorismo de estado (19761983), sus violaciones a los derechos humanos y las políticas de los movimientos de derechos humanos. El gobierno militar que asumió en marzo de 1976 se definió a sí mismo como salvador de la nación, concibiendo su misión como una lucha en contra del caos y la "subversión" que estaban destruyendo los valores e instituciones "naturales" de la argentinidad. Su tarea era, según su propia definición, la de devolver al país la "paz" y el "orden" frente al "caos" imperante. Para recuperar estos valores, era necesario proteger a la nación, a la familia y a las personas de los peligros de la "subversión". Los militares iban a liderar el "Proceso de Reorganización Nacional", convocando a los "padres, madres e hijos sanos de nuestro país" a que "cuiden el hogar. Preserven su seguridad. No acepten generosamente las ideas implantadas en las mentes jóvenes por expertos internacionales de la subversión... La seguridad y la paz del pueblo (...) se construye dentro del hogar y las escuelas." (La Nación, 19 de Junio, 1976, citado por Filc, 1997: 35).

\footnotetext{
${ }^{5}$ El exilio es una historia diferente. A menudo, el exilio era el resultado del compromiso político de los hombres, y las mujeres debieron acompañar a sus parientes, no como resultado de un proyecto político propio sino como esposas, hijas o madres. Los efectos de la experiencia del exilio en esas circunstancias sin duda son diferentes a los de exilios ligados a un proyecto político o un compromiso público propio. Como en otros temas, el carácter de género de la experiencia del exilio es un tema sobre el que poco se sabe.
} 
La referencia a la familia tradicional fue central en el encuadre interpretativo del gobierno militar. Primero, definió a la sociedad como un organismo constituido por células (familias). De esta forma, estableció un vínculo directo entre la estructura social y su raíz biológica, naturalizando los roles y valores familistas. Existía sólo una forma, la forma "natural", en la cual la sociedad argentina podía estar organizada. A partir de esta visión, los militares desarrollaron una masiva campaña para consolidar la unidad familiar, justificando su accionar en el lugar "natural" de la familia en el orden social. En la medida en que la metáfora de la familia era utilizada para la nación como un todo, el Padre-Estado adquirió derechos inalienables sobre la moral y el destino físico de los ciudadanos. La imagen de la nación como la "Gran Familia Argentina" implicaba que sólo los "buenos" chicos-ciudadanos eran verdaderamente argentinos. El discurso oficial representaba a los ciudadanos como niños inmaduros que necesitaban la disciplina que les iba a imponer un padre fuerte.

En este discurso, la autoridad paterna era fundamental. Se esperaba de los hijos e hijas que se comportaran acatando las obligaciones morales de obediencia - no había lugar para ciudadanos con derechos, para seres humanos con autonomía personal-. En un mundo como ese, "natural" más que social o cultural, el peligro del mal o de la enfermedad venía siempre desde afuera - algún cuerpo extraño que invade e infecta. Para restablecer el equilibrio natural, entonces, resultaba necesaria una intervención quirúrgica que permitiera extraer y destruir los tejidos sociales infectados-. El régimen militar, de esta forma, se transformaba en el padre protector que se hacía cargo de la ardua responsabilidad de limpiar y proteger a su familia, ayudado por otros padres "menores", a cargo de controlar y disciplinar a los adolescentes rebeldes. Las publicidades estatales en la televisión preguntarían: "¿Sabe Ud. dónde está su hijo ahora?", urgiendo a los padres a reproducir ad infinitum el trabajo de seguimiento, control e inteligencia que estaban llevando a cabo los militares.

La imagen de la familia como "célula" de la nación implicaba que los padres tenían que proteger a la célula-familiar de la penetración foránea, dado que un virus o bacteria que invade una única célula puede infectar al resto a través del contagio y la expansión. Los niños y los jóvenes representaban los lazos más frágiles o lábiles del cuerpo familiarnacional, y por contacto con el exterior podían traer la enfermedad al cuerpo social. La única manera de defender a la nación era confrontar al enemigo en el punto de entrada: el lazo entre los jóvenes y sus familias. En este punto, si el Padre-Estado estaba para proteger a la nación, no debía perder de vista el interior de la familia. En consecuencia, la vida privada familiar se veía avasallada por el poder público, y la distinción entre vida pública y familia privada desaparecía.

La defensa de la familia patriarcal tradicional era una política clara y explícita del gobierno (Filc, 1997). Al mismo tiempo, los militares implementaron una política sistemática de represión clandestina que afectó directamente a miles de familias. Esto implicaba secuestros masivos de personas -invadiendo inclusive los hogares - , para luego ser torturadas y desaparecidas (Calveiro, 1998, también CONADEP, 1984). Muchos niños y niñas también fueron secuestrados con sus padres y las mujeres embarazadas eran mantenidas con vida hasta que daban a luz. Con identidades cambiadas, los bebés eran apropiados por personal militar y otros ligados a sus rangos. Las estimaciones sobre el número de desaparecidos varían, con cifras que llegan a los 30.000; las estimaciones de bebés secuestrados o nacidos en cautiverio entregados con identidades falsas llegan a los 500 (de éstos, hasta 2010 los casos resueltos superan el centenar).

En 1976, los parientes de personas detenidas y desaparecidas se reunieron y formaron la organización Familiares de Detenidos y Desaparecidos por Razones Políticas. Abril de 1977 marcó el inicio de las reuniones de lo que más tarde se transformó en el emblema del movimiento de derechos humanos, las Madres de Plaza de Mayo. En noviembre del mismo año fue creada la Asociación de Abuelas de Plaza de Mayo.

¿Por qué debían ser planteadas en términos de parentesco las denuncias y demandas del movimiento de derechos humanos? En el contexto político de la dictadura, la represión y la censura, las organizaciones políticas y los sindicatos estaban suspendidos. El uso que el discurso dictatorial hacía de la familia como unidad natural de la organización social tuvo entonces su imagen en espejo en parte del movimiento de derechos humanos - la denuncia y 
protesta de los familiares era, de hecho, la única que podía ser expresada. Después de todo, eran madres que buscaban a sus hijos...-.

La dictadura atribuía a los padres la responsabilidad final de prevenir que sus hijos e hijas se convirtieran en subversivos/as. Cuando los padres y madres de los/as desaparecidos/as se acercaban al gobierno preguntando por el destino de sus hijos/as, la respuesta era una acusación: no sabían lo que estaban haciendo sus hijos/as porque no habían estado ejerciendo debidamente su autoridad paterna; si los y las jóvenes se transformaban en "subversivos/as" se debía a las deficiencias en la crianza familiar.

De esta forma, la paradoja del régimen militar argentino de 1976-1983 (con similitudes en los otros regímenes militares del Cono Sur en esa época) fue que el lenguaje y la imagen de la familia constituían la metáfora central del gobierno militar, pero también la imagen central del discurso y las prácticas del movimiento de derechos humanos. ${ }^{6}$ Lo que estaban denunciando eran crímenes en contra de la familia, proyectando al mismo tiempo una imagen de "buen hijo" del/a joven desaparecido/a y de una vida familia "normal". La imagen paradigmática es aquella de la madre simbolizada por las Madres de la Plaza de Mayo con sus pañuelos en la cabeza, la madre que deja la esfera privada "natural" de su vida familiar para invadir la esfera pública buscando a su hijo o hija secuestrado/a-desaparecido/a. ${ }^{7}$ Los Familiares, las Madres y las Abuelas a partir de los años setenta, H.I.J.O.S. (Hijos de los Desaparecidos) constituidos veinte años después y Hermanos en el siglo XXI, son las organizaciones que mantienen activas sus demandas por justicia, verdad y memoria. Lo que es significativo aquí es que estas organizaciones entran en la esfera pública no como metáforas o imágenes simbólicas de los lazos familiares, sino en un sentido literal (y biológico) de las relaciones de parentesco.

A pesar de sus orientaciones contrapuestas y en conflicto, ambas partes hablaban en la clave familiar de los lazos naturales y cercanos. Para unos, la familia era el control y la autoridad, presentados y enmascarados en términos de protección contra las amenazas y el mal. Para los/as otros/as, el lazo familiar personalizado y privado justificó y motivó la acción pública, con un doble propósito: por un lado, revertir la imagen de "mala familia" que los militares querían transmitir en relación con las familias de las víctimas. Los/as desaparecidos/as y detenidos/as eran presentados/as por sus familiares como niños y niñas ejemplares, buenos/as estudiantes y miembros de las familias viviendo en armonía; en suma, como seres superiores, o al menos "normales". Por otro lado, la pérdida familiar impulsó la salida de los lazos y sentimientos privados hacia la esfera pública, rompiendo decisivamente la frontera entre la vida privada y el ámbito público.

Esta aparición pública de los lazos familiares en la vida política es significativa, más allá de sus propios objetivos y de este caso específico de su presencia. Implica una reconceptualización de la relación entre vida pública y privada. En la imagen que el movimiento de derechos humanos comunicó a la sociedad, el lazo de la familia con la víctima era la justificación básica que da legitimidad para la acción. Para el sistema judicial, en realidad era el único. Sólo las víctimas sobrevivientes y los parientes directos son considerados "afectados" en sus demandas de reparación — personalizadas e indivi-

\footnotetext{
${ }^{6}$ En verdad, la denuncia de la represión política en Argentina no fue patrimonio exclusivo de las organizaciones de familiares. Lo que es conocido como el "movimiento de derechos humanos" fue muy heterogéneo desde su propio nacimiento, aun antes de la dictadura militar. Además de familiares directos de víctimas, incluía a personas progresistas y con una ética humanista, fueran ellas intelectuales, políticos/as, autoridades religiosas de distintas iglesias, ciudadanos y ciudadanas preocupados/as por el rumbo de los acontecimientos políticos del país. Se agruparon en diversas organizaciones, tales como la Asamblea Permanente por los Derechos Humanos, la Liga Argentina de los Derechos del Hombre, el Servicio de Paz y Justicia, y más tarde el Movimiento Ecuménico por los Derechos Humanos y el Centro de Estudios Legales y Sociales, entre otras organizaciones. Un análisis de esta historia del movimiento se encuentra en Jelin, 1995 y Jelin, 2005.

${ }^{7}$ La pregunta “ipor qué madres y no padres?” remite a dos respuestas habituales: primero, que ser madre otorga más seguridad frente al terror ya que todos — inclusive los militares - respetan la maternidad como algo sagrado; además, que alguien (el hombre jefe de hogar) debe seguir trabajando para mantener a la familia. Como la trágica realidad lo mostró pocos meses después de la primera ronda de las Madres, su status materno no les otorgó ningún privilegio: en diciembre de 1977 desaparecían varias Madres. También hay que recordar que no todas ellas eran amas de casa, como la imagen popular ha cristalizado. El tema, sin duda, merece investigaciones de mayor profundidad.
} 
dualizadas - Sin embargo, este familismo público y político plantea dificultades y peligros en términos de su impacto cultural y político. Las Madres pueden haber generalizado su maternidad, con el slogan de que todos los desaparecidos son hijos de todas las Madres. Al mismo tiempo, y como efecto de esta interpretación de la noción de familia, se crea una distancia -imposible de superar- en las movilizaciones públicas entre quienes llevan la "verdad" del sufrimiento personal y privado y aquellos que se movilizan políticamente por la misma causa, pero presumiblemente por otros motivos, que no son vistos como igualmente transparentes o legítimos. Es como si en la esfera pública del debate, la participación no es igualitaria sino estratificada de acuerdo a la exposición pública del lazo familiar; razones ideológicas, políticas o éticas no parecen tener el mismo poder justificatorio a la hora de actuar en la esfera pública, excepto "acompañando" las demandas de los "afectados directos".

\section{EL GÉNERO EN LAS MEMORIAS}

En los períodos de transición posteriores a las dictaduras y al Terrorismo de Estado, los procesos de recuperación y de reconstrucción de lo ocurrido tienen en el testimonio una fuente privilegiada. Los registros documentales y los archivos son escasos - por la clandestinidad de la represión, por la destrucción y el ocultamiento como práctica generalizada en el momento de la caída de los regímenes dictatoriales - El testimonio personal de víctimas de prisiones y exilios, de sobrevivientes de campos clandestinos, de familiares y testigos, se torna una fuente fundamental para saber qué ocurrió. Frente a comisiones investigadoras que registran denuncias o en juicios a victimarios que requieren testimonios en sedes judiciales, como declaraciones necesarias para políticas de reparación económica, registros en archivos de historia oral o expresiones públicas en entrevistas, autobiografías, películas documentales y otros soportes, la voz en primera persona ha ganado un lugar muy especial en las expresiones públicas de las memorias del terror.

Sin duda, hay una diferenciación clara en el testimonio según el encuadre institucional en el que se genera. El testimonio judicial sigue un libreto y un formato preestablecidos, ligados a la noción de prueba jurídica, fáctica, fría, precisa. En general, los testimonios orales realizados en ámbitos públicos, transcriptos para "materializar la prueba", se enmarcan en una expectativa de justicia y cambio político. Si bien el testimonio en esos ámbitos puede tener como efecto el empoderamiento y legitimación de la voz de la víctima, su función "testimonial" está centrada en la descripción fáctica, hecha con la mayor precisión posible, de la materialidad de la tortura y la violencia política. Cuanta menor emocionalidad e involucramiento del sujeto que narra, mejor, porque el testimonio oral tiene que reemplazar a las "huellas materiales" del crimen. Este tipo de testimonio público se diferencia significativamente de otros - sean los recogidos por archivos históricos, los solicitados por investigadores/as, los textos testimoniales escritos por sobrevivientes, testigos y víctimas, y las representaciones literarias y performáticas, más distanciadas de la literalidad de los acontecimientos ocurridos en el pasado (Taylor, 1997, cap. 6; Pollak y Heinich, 2006; Pollak 1990)-.

Estos encuadres sociales están cruzados por relaciones de género, tanto en lo referente al tipo de actividad que hombres y mujeres tuvieron como a las subjetividades genéricas. La experiencia indica que mujeres y hombres desarrollan habilidades diferentes en lo que concierne a la memoria. En la medida en que la socialización de género implica prestar más atención a ciertos campos sociales y culturales que a otros y definir las identidades ancladas en ciertas actividades más que en otras (trabajo o familia, por ejemplo), es de esperar un correlato en las prácticas del recuerdo y de la memoria narrativa: las mujeres tienden a recordar eventos con más detalles mientras que los varones tienden a ser más sintéticos en sus narrativas; las mujeres expresan sentimientos mientras que los hombres relatan más a menudo en una lógica racional y política; las mujeres hacen más referencias a lo íntimo y a las relaciones personalizadas - sean ellas en la familia o en el activismo político- Ellas tienden a recordar la vida cotidiana, la situación económica de la familia, lo que se suponía que debían hacer en cada momento del día, lo que ocurría en sus barrios y comunidades, sus miedos y sentimientos de inseguridad. Recuerdan en el marco de relaciones familiares, porque el tiempo subjetivo de las mujeres está organizado y ligado a los hechos reproductivos y a los vínculos afectivos (Leydesdorff, Passerini y Thompson, 1996). 
En el caso de las memorias de la represión, además, muchas mujeres narran sus recuerdos en la clave más tradicional del rol de mujer, la de "vivir para los otros", ligado a una identidad centrada en atender y cuidar a otros cercanos, generalmente en el marco de relaciones familiares. La ambigüedad de la posición de sujeto activo/acompañante o cuidadora pasiva puede entonces manifestarse en un corrimiento de su propia identidad, queriendo "narrar al otro". Esto implica una elección de ser testigo-observadora del protagonismo de otro/a (un hijo detenido-desaparecido, por ejemplo), negando o silenciando el testimonio de sus propias vivencias - aunque obviamente estas se "cuelan" en relatos que aparentemente están centrados en la experiencia de otros-.

Cuando la referencia es la tortura y la cárcel, las experiencias personales están fuertemente marcadas por la centralidad del cuerpo. La posibilidad de incorporarlas al campo de las memorias sociales presenta una paradoja: el acto de la represión violó la privacidad y la intimidad, quebrando la división cultural entre el ámbito público y la experiencia privada. Superar el vacío creado por la represión implica la posibilidad de elaborar una memoria narrativa de la experiencia, que necesariamente es pública, en el sentido de que debe ser compartida y comunicada a otros, especialmente cuando se produce en un espacio institucional legitimado para el caso, frente a "otros/as" que, en principio, pueden comprender y cuidar. Sin embargo, siguen siendo "otros/as", una alteridad. Al mismo tiempo, la recuperación de la "normalidad" de la vida implica, en el mundo moderno, la reconstrucción de un sí mismo, la reconstrucción de la intimidad y la privacidad. Esta reconstrucción involucra entonces el control, por parte del sujeto, de sus silencios en las narrativas personales. Estos silencios no son olvidos, sino opciones personales como "un modo de gestión de la identidad" (Pollak y Heinich, 1986: 5), ligado al proceso de "recuperar la vergüenza" (Amati Sas, 1991).

¿Cómo combinar la necesidad de construir una narrativa pública que al mismo tiempo permita recuperar la intimidad y la privacidad? Se plantea aquí una encrucijada ética en relación a este tipo de me- morias sociales. ¿Cuánto contar? ¿Cuánto pedir que se cuente? En la época que nos toca vivir, en la cual a través de los medios de comunicación de masas se plantea una "publicización" de la vida privada en los "talk shows" y los "reality shows" que banalizan los sentimientos y la intimidad, se corre el riesgo de que el género testimonial caiga en la exposición (¿excesiva?) y en la espectacularización del horror. El terrorismo de Estado y la represión violaron la intimidad y los cuerpos humanos; la reconstrucción de la identidad requiere reconstruir también los espacios privados y la intimidad. En este contexto, las "modas" testimoniales o, como lo llama Wiewiorka (1998), "la era del testimonio", presenta peligros sobre los que hay que alertar, ya que a menudo parece orientarse a exponer públicamente intimidades, lo cual puede indicar las dificultades en esta reconstrucción de quien narra y un efecto de saturación en quien escucha.

Por otro lado, la importancia personal e individual de hablar y encontrar una escucha no reemplazan a los otros planos de los trabajos de la memoria. La ola testimonial no toma el lugar de las respuestas políticas, institucionales y judiciales a la conflictividad del pasado, sino que por lo general se estimulan y refuerzan entre sí.

\section{LAS PARADOJAS DE LA ESCUCHA INSTITUCIONAL}

El plano institucional estatal y la subjetividad del testimonio personal confluyen en una instancia particular, la de la recolección de testimonios y audiencias de las comisiones investigadoras. Desprovistas de las formalidades y rigideces del encuadre judicial que tiene patrones muy controlados y precisos anclados en la sustanciación de la prueba jurídica, las comisiones ofrecen un espacio más abierto, más protegido para la transmisión de experiencias sin la necesidad de controlar las emociones ni de cuidar las palabras. ${ }^{8}$

Parecería entonces que el encuadre propuesto por Comisiones de Verdad es especialmente propicio para el testimonio de las mujeres. Debemos re-

\footnotetext{
${ }^{8}$ Esto llevó inclusive a algunos/as autores/as a sostener la ventaja institucional de promover comisiones antes que juicios en los períodos de transición (Minow, 1998, por ejemplo).
} 
cordar, sin embargo, que la dimensión de género no fue incorporada explícitamente por las comisiones investigadoras -oficiales y no oficiales - de los años ochenta y noventa. Solamente en el siglo XXI ocurrió un cambio significativo en esta dirección, y la consideración de género se incorporó de manera explícita en el trabajo de las comisiones en la región.

Permítaseme tomar un caso significativo de preocupación y promoción de la voz de las mujeres, el de la Comisión de Verdad y Reconciliación (CVR en adelante) de Perú, que actuó entre 2000 y 2003 (www.cverdad.org.pe). La Comisión hizo un esfuerzo especial para contar con testimonios sobre violencia hacia las mujeres, en contraste con la CONADEP en Argentina o la Comisión de Verdad y Reconciliación de Chile, cuyas actividades no fueron diseñadas o llevadas a cabo con una sensibilidad de género. Aunque no había consideraciones específicas en el mandato de la Comisión peruana, los esfuerzos de las feministas llevaron a incorporar los delitos sexuales y a establecer una Línea de género en su trabajo. Así, con el objetivo explícito de registrar las voces de mujeres, se intentó romper con la idea de que "las mujeres no hablan". El 54\% del total de testimonios - el $64 \%$ de los obtenidos en Ayacucho - fueron ofrecidos por mujeres (CVR, vol. VIII: 64).

El grupo de género de la Comisión sabía que cuando hablan, las mujeres tienden a describir los sufrimientos de sus parientes y las disrupciones de las rutinas cotidianas. A menudo, los detalles de estos sufrimientos se ubican en un tiempo de larga duración y en el contexto de injusticias más permanentes. En consecuencia, el interés de la Comisión consistía en que las mujeres hablasen "de sí mismas". Se elaboraron estrategias específicas para captar las experiencias de violencia de las mujeres, tales como documentos de entrenamiento especial para el personal, audiencias públicas específicas sobre el tema, etc. (Mantilla 2005; Henríquez 2006). La "sensibilidad de género" implicó una preocupación especial por obtener testimonios de violencia sexual y violación, aunque la definición de violencia sexual utilizada fue amplia: “(...) es un tipo de violación de derechos humanos, e incluye la prostitución forzada, las uniones forzadas, la esclavitud sexual, abortos y desnudez forzados". (CVR, vol. VIII: 89)

Está claro que las mujeres hablaron, pero no necesariamente de su propia condición de víctimas o de la violencia sexual. ${ }^{9}$ Los informes de primera mano son difíciles de encontrar en cualquier lugar; por lo general, lo que se hallan son informes de lo que pasaba o de lo que le pasó a "otras" mujeres. ${ }^{10}$ Sin embargo, en base a la evidencia cualitativa recogida, la CVR pudo establecer que la violencia sexual fue una práctica generalizada durante el conflicto armado. Pero esta violencia sexual durante los conflictos armados en el Perú debe ser leída en el marco de un contexto histórico de creencias enraizadas sobre las relaciones raciales y de género. ${ }^{11}$

¿Por qué las mujeres lo mencionan como testigos y no como víctimas? ${ }^{12}$ Las explicaciones incluyen la vergüenza y la culpa; también el hecho de que la violación nunca era un acto único o aislado - era parte de otras atrocidades como asesinatos y masacres, robos y secuestros de niños, y el testimonio sobre éstas puede opacar el del acto de violación (Mantilla, 2005) — . Theidon alude también al "continuo guerra-paz de violencia hacia las mujeres", y a la "especialización de género en la memoria".

En las descripciones densas que hacen las mujeres, narran un conjunto amplio de verdades acerca de las injusticias sistemáticas, las violaciones a sus derechos socioeconómicos, las marcas lacerantes

\footnotetext{
${ }^{9}$ De 17.000 testimonios, el número de violaciones denunciadas fue relativamente bajo: sólo 538. El 83\% de éstas fueron perpetradas por las Fuerzas Armadas.

${ }^{10}$ Este es el caso, por ejemplo, de los testimonios de mujeres detenidas en la ESMA (Calveiro, 1998; Actis et al., 2001). En testimonios de sobrevivientes de la ESMA se cuentan violaciones por parte de los perpetradores, pero siempre refiriéndose a otra persona. La figura de la "traidora", que traiciona a sus propios compañeros políticos y hasta llega a enamorarse de su torturador, es una imagen recurrente en diferentes casos. Las representaciones literarias de esta imagen son analizadas por Longoni (2004) para el caso argentino y por Richard (1998) para el caso chileno.

${ }^{11}$ Kimberly Theidon habla de "racing rape" (racializar la violación), refiriéndose a los insultos étnicos que los soldados les propinaban a las mujeres mientras las violaban. A través de insultos tales como "india", los soldados — cholos en su mayoría— les transferían el estigma a las mujeres (Theidon, 2007).

${ }^{12} \mathrm{El}$ análisis de las voces de las mujeres en relación a la violencia sexual que presento aquí se apoya fuertemente en la investigación y la interpretación de Kimberly Theidon (2007).
} 
de la discriminación étnica, y la futilidad de buscar justicia en sistemas legales. (...) Cuando las mujeres hablan del sufrimiento de los miembros de sus familias y comunidades, (...) cuando recuerdan con indignación cómo fueron sometidas a insultos étnicos (...) -están hablando de sí mismas y de las dimensiones de género de la guerra (Theidon, 2007: 473)—.

La característica de las Comisiones de Verdad es que están centradas en las víctimas, dentro del marco interpretativo de las "violaciones a los derechos humanos" que pone atención especial en la integridad física. Esto crea una tensión entre el informe en primera persona de la "víctima individual" y el carácter más totalizador de la memoria de las mujeres. Hay poco lugar para narrativas del heroísmo de las mujeres, de su participación en la defensa de sus comunidades y sus familias. Al final, el foco sobre las categorías de victimización para organizar la masa de información que se debe manejar produce narrativas estandarizadas y normalizadas; produce el silencio de otras experiencias que no se ajustan al marco preestablecido: "Hay una cierta ironía; las comisiones tienen que investigar la verdad, y sin embargo las verdades más amplias que narraban las mujeres eran frecuentemente reducidas al daño sexual experimentado (...). Las comisiones deben salir de la lógica centrada en la víctima para abrir un espacio narrativo que permita a las mujeres expresar un testimonio que no esté limitado al sufrimiento y al duelo. De este modo, la 'sensibilidad de género' se centraría menos en las estrategias elaboradas para que las mujeres hablen de 'sus' violaciones y más en desarrollar maneras nuevas de escuchar lo que las mujeres tienen para decir sobre la guerra" (Theidon, 2007: 474).

Sin duda, el informe de la CVR expuso la violencia sexual que ocurrió durante el conflicto. La secuela inquietante es la posibilidad de que se re- fuercen los estereotipos de género que ubican a las mujeres como víctimas, silenciando su potencial y su rol activo en la sociedad. En Perú no ha habido una discusión pública del significado de este tema ni una respuesta social o política a estas dolorosas experiencias. La presencia de testimonios en el informe no ha llevado a una incorporación de esta preocupación en programas educativos o en formas de reparación. La documentación de las atrocidades según la categorización de la CVR está allí para ser leída por quienes tienen interés en hacerlo; al mismo tiempo, las memorias quedan en el ámbito de las experiencias personales, sin producir transformaciones simbólicas o materiales en las relaciones de género.

En Chile, más de una década después de la presentación del informe de la Comisión de Verdad y Reconciliación, el presidente Ricardo Lagos promovió la formación de una Comisión nacional sobre Prisión Política y Tortura, que iba a recibir denuncias sobre crímenes que no habían sido cubiertos por la comisión anterior. ${ }^{13}$ En este caso, hubo un esfuerzo especial por recibir denuncias de mujeres, y por escuchar testimonios de delitos sexuales. ${ }^{14}$

La violación como práctica sistemática de represión y violencia cobró visibilidad internacional en las reuniones paralelas a la Conferencia Internacional de Derechos Humanos de Viena en 1993. Allí, el testimonio de la violación como parte de la violencia en el conflicto de la ex Yugoslavia ingresó al escenario de debate de la comunidad internacional de derechos humanos (Mostov, 2000). El camino para el reconocimiento como crimen no es sencillo, porque implica testimonios de violaciones a la intimidad, al cuerpo, a la integridad personal. Las pruebas no son fácilmente obtenibles. Siguiendo con la línea de reflexión presentada más arriba, la paradoja reside en que la reconstrucción personal requiere reconstruir un espacio propio de intimidad, un sentimiento de vergüenza y de protección de los propios "secretos",

\footnotetext{
${ }^{13}$ La Comisión formada al inicio de la transición (1990), conocida como Comisión Rettig, tuvo el mandato de investigar desapariciones y ejecuciones. La Comisión sobre tortura (conocida como Comisión Valech) debía recibir testimonios de tortura y encarcelamiento. El informe Rettig se encuentra en www.ddhh.gov.cl/ddhh_rettig.html. A la fecha de escribir este texto (agosto de 2010) el informe Valech había sido eliminado de Internet por el gobierno chileno, y se encuentran numerosas denuncias de este hecho y pedidos de revertir esta decisión.

${ }^{14}$ Fueron recibidas alrededor de 37.000 denuncias. Entre ellas, hay 316 denuncias de violación, con varios casos de embarazos que resultaron en abortos y en nacimientos.
} 
y al mismo tiempo la manera de encarar la denuncia implica un grado de exposición pública del cuerpo y de la intimidad que contradice esa necesidad de protección. Sin duda, en la última década ha habido un mayor reconocimiento de la violación como práctica de guerra y de represión, incluyendo su caracterización como "crimen de lesa humanidad". ${ }^{15}$

\section{EL FAMILISMO Y EL MATERNALISMO EN LA ESFERA PÚBLICA}

En suma, nos encontramos con un panorama político cultural en el que las memorias de la represión política reproducen los estereotipos de género, donde el familismo se mantiene como marco interpretativo central de los lazos sociales. ${ }^{16}$ ¿Podían haber sido diferentes las experiencias post-dictatoriales? ¿Existen espacios para un enfoque que supere los estereotipos de género? ¿Para una perspectiva que permita contribuir a la construcción de ciudadanía basada en un principio de igualdad? ¿Es la legitimidad de la voz testimonial un obstáculo para tal proceso? Teóricamente no tiene por qué serlo. Pero la visibilidad y legitimidad de las voces ancladas en la perdida familiar y en la vivencia corporal de la represión parecen delinear un escenario político que define las nociones de "afectado/a" y "ciudadano/a" como antagónicas, dando preeminencia a la primera.

¿De dónde sale el familismo y la maternalidad política? ¿De dónde la visión de víctima pasiva de las mujeres? Como conjunto de valores y creencias, sus raíces pueden ser rastreadas en la historia cultural y política de la región. En Argentina y en otros países latinoamericanos, la Iglesia Católica ha sido un actor cultural poderoso desde la época colonial. Su punto de vista central concibe a la familia "natural" como "célula básica" de la sociedad, y contiene una fuerte tradición cultural del "Marianismo" (la primacía cultural de la maternidad encarnada en la figura de la Virgen María). Este conjunto de creencias ha guiado las políticas y programas del Estado argentino en relación con la vida familiar y la relación entre familia y esfera pública. ${ }^{17}$ También, durante la última parte del siglo XIX y la primera mitad del siglo XX, los inmigrantes europeos trajeron consigo la expectativa de progreso y movilidad ascendente - no en la forma de una idea individualista del "self-made man" sino más bien una movilidad basada en términos familiares intergeneracionales-. Los inmigrantes no eran individuos aislados en búsqueda de progreso; eran parte de una amplia red familiar y comunitaria regida por vínculos de solidaridad, reciprocidad y responsabilidad mutua. El mismo patrón persistió en las corrientes migratorias posteriores originadas en otros países latinoamericanos. En suma, la ética de la vida familiar tiene fuertes antecedentes históricos.

En términos más amplios, el familismo involucra una base personalizada y particularista para las solidaridades interpersonales y políticas. No se trata de una relación abstracta y anónima; debe haber una relación personal que ata a ambas caras de la relación: pueden ser vínculos jerárquicos y redes familiares patriarcales o, al extender el familismo más allá de los vínculos de sangre hacia la vida pública y políti$\mathrm{ca}$, vínculos verticales de patronazgo personalizado.

Nadie duda del dolor de las víctimas, ni del derecho de los familiares (y de la sociedad en su conjunto) a recuperar la información sobre lo que ocurrió durante un régimen represivo. Tampoco quedan

\footnotetext{
${ }^{15}$ El tema llegó a la atención del Consejo de Seguridad de Naciones Unidas hacia fines de 1992, por las violaciones en el conflicto de la ex Yugoslavia. La primera condena internacional de violencia sexual como crimen de lesa humanidad fue en 1998, en relación con el genocidio de Ruanda. En el Estatuto de Roma del Tribunal Penal Internacional (ICC) se incluye la violación, la esclavitud sexual, la prostitución forzada, el embarazo forzado, la esterilización forzada o "cualquier otra forma de violencia sexual de gravedad comparable" como crimen de lesa humanidad cuando se cometa de forma generalizada o sistemática. http://www.un.org/spanish/ preventgenocide/rwanda/sexualviolence.shtml consultado el 23/8/2010. En Argentina, el primer fallo en establecer la violación como delito de lesa humanidad fue en abril de 2010, en una sentencia del Tribunal Oral Federal de Santa Fe. En la sentencia, los jueces consideraron que la violencia sexual que ejerció el represor constituye una forma de tormentos y, por ende, es un crimen contra la humanidad. "Violencia sexual es lesa humanidad", Página 12, 23 de abril de 2010, suplemento Las 12:1.

${ }^{16}$ En este trabajo, no presentamos el análisis de otra faceta de la presencia familiar genéticamente definida en este campo: los análisis de ADN para la identificación de niños y niñas secuestrados/as y nacidos en cautiverio. Para este tema, Jelin, 2007.

${ }^{17}$ Para una historia del maternalismo en la vida política argentina, Nari, 2004. El análisis comparativo de las políticas de familia y género durante las dictaduras de Argentina, Chile y Brazil, Htun, 2003.
} 
dudas sobre el rol de liderazgo que las víctimas directas y sus familiares han tenido en Argentina y en otros lugares como voces centrales en la denuncia de la represión y en su lugar en las demandas de verdad y justicia. Ni de la importancia que tuvieron y siguen teniendo las mujeres en esta lucha. La cuestión es aquí otra, y en realidad es una cuestión doble. Por un lado, se trata de ver hasta qué punto la experiencia colectiva de dictadura y represión impactó en el sistema de relaciones de género. Por el otro, la cuestión es la aparente paradoja planteada por la convergencia entre el parentesco y la ciudadanía: en la elaboración de las memorias de la dictadura, tienen un protagonismo central los vínculos de parentesco - al punto de definir la legitimidad de la voz en la esfera pública - y al hacerlo, se refuerza una ideología familista y maternalista; al mismo tiempo, esto dificulta la formación de un colectivo ciudadano amplio que se haga cargo y asuma como propias las memorias de la represión.

La cuestión de las voces de la memoria y de la verdad puede llegar a tener una dimensión aún más inquietante. Existe el peligro (especular en relación con el biologismo racista) de anclar la legitimidad de quienes expresan la verdad en una visión esencializadora de la biología y del cuerpo. El sufrimiento personal (especialmente cuando se lo vivió en "car- ne" propia o a partir de vínculos de parentesco sanguíneo, donde la maternidad es emblemática) puede llegar a convertirse para muchos en el determinante básico de la legitimidad y de la verdad. Paradójicamente, si la legitimidad social para expresar la memoria es socialmente asignada a quienes tuvieron una experiencia personal de sufrimiento corporal o a sus familiares, esta autoridad simbólica puede fácilmente deslizarse (consciente o inconscientemente) a un reclamo monopólico del sentido y del contenido de la memoria y de la verdad. El nosotros reconocido es, entonces, excluyente e intransferible. En el extremo, este poder puede llegar a obstruir los mecanismos de ampliación del compromiso social con las memorias, al no dejar lugar para la reinterpretación y la resignificación - en sus propios términos - del sentido de las experiencias transmitidas.

El desafío histórico, entonces, reside en el proceso de construcción de un compromiso cívico con el pasado que sea más democrático y más inclusivo. Las preguntas "ejemplificadoras" (en el sentido de Todorov, 1998) permanecen. ¿Hasta qué punto pueden la memoria y la justicia en relación al pasado servir para ampliar el horizonte de experiencias y expectativas? ¿En qué medida pueden ser reestructuradoras de relaciones de género que victimizan a las mujeres y "feminizan" a las víctimas?

\section{REFERENCIAS BIBLIOGRÁFICAS}

Actis, Manú; Aldini, Cristina; Gardella, Liliana; Lewin, Miriam y ToKar, Elisa (2001), Ese infierno. Conversaciones de cinco mujeres sobrevivientes de la ESMA, Buenos Aires: Sudamericana.

Aмati Sas, Silvia (1991), "Recuperar la vergüenza”. En Puget, Janine y Kaës, René (eds.), Violencia de estado y psicoanálisis, Buenos Aires: Centro Editor de América Latina.

BAL, Mieke (1999), “Introduction”. En Bal, Mieke, Crewe, Jonathan y Spitzer, Leo (eds.), Acts of memory. Cultural recall in the present, Hanover - Londres: University Press of New England.

Bunster, Ximena (1991), "Sobreviviendo más allá del miedo". En La mujer ausente. Derechos humanos en el mundo, núm. 15, Santiago: Isis Internacional.

Calveiro, Pilar (1998), Poder y desaparición. Los campos de concentración en Argentina, Buenos Aires: Colihue.

Ciollaro, Noemí (1999), Pájaros sin luz. Testimonios de mujeres de desaparecidos. Buenos Aires: Planeta.

FILC, Judith (1997), Entre el parentesco y la política. Familia y dictadura, 1976-1983, Buenos Aires: Biblos.

Franco, Jean (1992), “Gender, Death and Resistence: Facing the Ethical Vacuum”. En Corradi, Juan, Patricia Weiss Fagen y Manuel A. Garretón (eds.), Fear at the edge. State terror and resistance in Latin America. BerkeleyOxford: University of California Press.

Henríquez Ayín, Narda Z. (2006), Cuestiones de género y poder en el conflicto armado en el Perú. Lima: CONCYTEC. Htun, Mala (2003). Sex and the State. Abortion, Divorce and the Family under Latin American Dictatorships and Democracies. Cambridge: Cambridge University Press. 
JELIN, Elizabeth (1995), "La política de la memoria: El movimiento de derechos humanos y la construcción democrática en la Argentina”. En Carlos H. Acuña et al., Juicio, castigos y memoria: Derechos humanos y justicia en la política argentina. Buenos Aires: Nueva Visión.

Jelin, Elizabeth (2002), Los trabajos de la memoria. Madrid y Buenos Aires: Siglo XXI de España Editores y Siglo XXI de Argentina Editores.

JELIN, Elizabeth (2005), "Los derechos humanos entre el estado y la sociedad.” En Juan Suriano, ed., Nueva Historia Argentina, vol. 10. Buenos Aires: Editorial Sudamericana.

JELIN, Elizabeth (2007), "Víctimas, familiares y ciudadano/as: las luchas por la legitimidad de la palabra", Cadernos $P A G U, 29$. Dossier Repensando relacoes familiares. Campinas: Núcleo de Estudos de Genero.

Koselleck, Reinhart (1993), Futuro pasado: para una semántica de los tiempos históricos, Barcelona: Paidós.

LACAPra, Dominique (2001), Writing history, writing trauma. Baltimore: The Johns Hopkins University Press.

Laub, Dori (1992b), "Bearing Witness, or the Vicissitudes of Listening”. En Felman, Shoshana y Laub, Dori, Testimony. Crises of Witnessing in Literature, Psychoanalysis, and History, Nueva York: Routledge.

Leydesdorff, Selma, Passerini, Luisa y Thompson, Paul (1996), “Introduction”. En Leydesdorff, Selma, Passerini, Luisa y Thompson, Paul (eds.), Gender and Memory, Oxford: Oxford University Press.

Longoni, Ana (2004), “Traiciones. La figura del traidor (y la traidora) en los relatos acerca de los sobrevivientes de la represión”, en Elizabeth Jelin y Ana Longoni (comps.) Escrituras, imágenes, escenarios ante la represión. Madrid y Buenos Aires: Siglo XXI de España Editores / Siglo XXI de Argentina Editores.

Mantilla, Julissa (2005), "La experiencia de la Comisión de la Verdad y Reconciliación en el Perú: Logros y dificultades de un enfoque de género". En Memorias de ocupación: Violencia sexual contra mujeres detenidas durante la dictadura. Santiago: Centro Regional de Derechos Humanos y Justicia de Género.

Minow, Martha (1998), Between vengeance and forgiveness. Boston: Beacon Press.

Mostov, Julie (2000), "Sexing the nation / Desexing the body: Politics of national identity in the former Yugoslavia". En Tamar Mayer (ed.), Gender ironies of nationalism. Sexing the nation. Londres-Nueva York: Routledge.

NARI, Marcela (2004), Politicas de maternidad y maternalismo político. Buenos Aires, 1890-1940. Buenos Aires: Biblos.

Pollak, Michael (1990), L'expérience concentrationnaire. Essai sur le maintien de l'identité sociale, París: Métailié.

PollaK, Michael (2006), Memoria, olvido, silencio. La producción social de identidades frente a situaciones límite. La Plata: Ediciones Al Margen.

Pollak, Michael y HeInich, Nathalie (2006), “El testimonio”. En Michael Pollak (2006), Memoria, olvido, silencio. La producción social de identidades frente a situaciones límite. La Plata: Ediciones Al Margen, pp. 53-112.

Richard, Nelly (1998), Residuos y metáforas. Santiago: Cuarto Propio.

SAlEssi, Jorge (1995), Médicos maleantes y maricas, Buenos Aires: Beatriz Viterbo Editora.

Tavares, Flávio (1999), Memórias do esquecimento, San Pablo: Globo.

TAYlor, Diana (1997), Disappearing Acts. Spectacles of Gender and Nationalism in Argentina's “Dirty War”, Durham - Londres: Duke University Press.

Theidon, Kimberly (2007), “Gender in Transition: Common Sense, Women and War”, Journal of Human Rights, 6(4): 453-478.

Todorov, Tzvetan (1998). Les abus de la mémoire. París: Arléa.

van Alphen, Ernst (1997), Caught by History. Holocaust Effects in Contemporary Art, Lliterature and Theory, California: Stanford University Press.

Wiewiorka, Annette (1998), L'ère du témoin. Paris: Plon. 